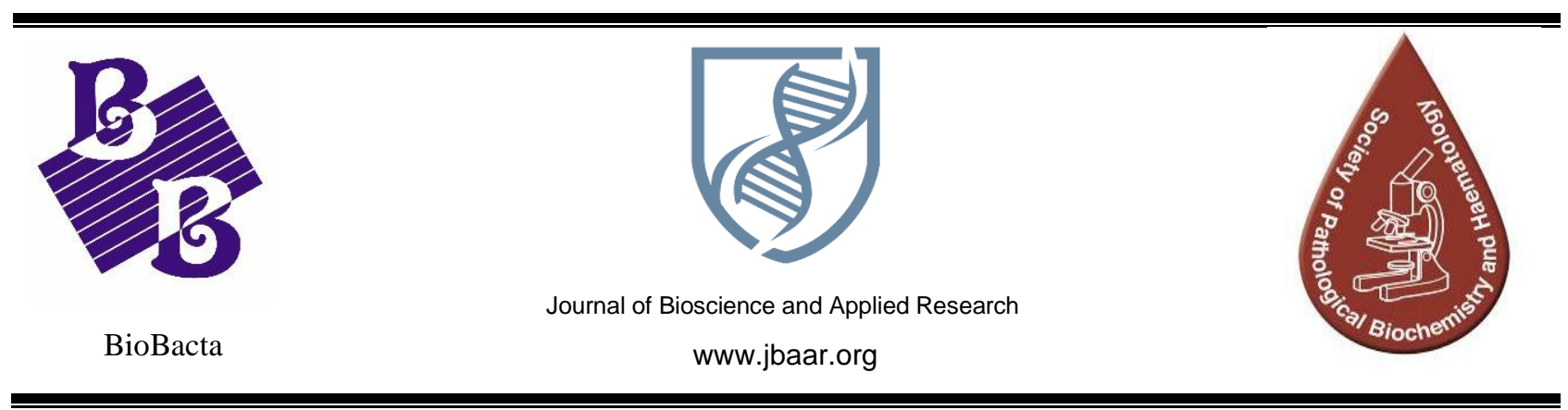

\title{
Berberine attenuates cancer cell growth via modulating the cell cycle dynamics but not apoptosis in human colorectal HCT-116 3D spheroid model
}

\author{
Ahmed A. Soffar \\ Division of Molecular Biology, Department of Zoology, Faculty of Science, \\ Alexandria University, Alexandria, Egypt \\ E-mail address: ahmedsoffar@gmail.com; ahmed.soffar@alexu.edu.eg \\ DOI: 10.21608/jbaar.2019.146799
}

\begin{abstract}
:
Colorectal carcinoma is a cosmopolitan type of cancer with a poor prognosis, motivating seeking novel strategies to prevent disease development and progression. The poor prognosis is attributed to the severe toxic side effects of the current therapeutic regimes. Hence, novel less toxic treatment strategies are urgently warranted. Berberine is a natural compound with several biological and pharmacological properties, including anti-fungal, anti-diabetic, cardioprotective effects. Some reports showed that berberine inhibits cell growth by inducing cell cycle arrest and promotion of apoptosis in cancer cells. Importantly, the anticancer potential of berberine in colorectal cancer has not been previously investigated. Hence, this work aims to investigate whether berberine possesses anticancer properties against colorectal HCT116 cancer cells. The potential effect of berberine on cell cycle regulation and apoptosis will also be deeply investigated. This work was conducted using the more physiological 3D spheroid culture model that mimics better the impact of the tumor microenvironment as well as the cell-cell interaction in the cellular response to therapy. When compared to the previous studies, this work will explain the mode of action of berberine in more physiological conditions that better mimics the in vivo situation. To achieve the goal of this work, spheroid growth assay, as well as proliferation assay, were performed. Spheroid cell suspensions were further investigated using flow cytometry to assess the cell cycle distribution of cells upon berberine application. BrdU immunostaining was performed to elucidate the S-phase fraction of cells. The proliferation potential and the level of apoptosis were also investigated by Ki67 and Annexin V labeling, respectively. The results showed that berberine attenuated tumor spheroid growth and limits the proliferative capacity of HCT116 cells. This could be attributed to the berberine-mediated G1-phase cell cycle delay. The S-phase fraction of cells was significantly decreased upon berberine application. Unexpectedly, berberine did not induce a significant difference in the \% of apoptotic cell fraction of cells as compared to the controls. Collectively, these results suggest that berberine possesses an anti-tumor efficacy in 3D culture preparations via modulating the cell cycle progression. Specifically, berberine induces G1-phase cell cycle delay and decreases the S-phase fraction of cells. Thus, it limits the proliferative capacity of cells. Also, berberine did not induce programmed cell death in the HCT116 spheroids.
\end{abstract}

Keywords: Berberine, Cell cycle, Apoptosis, Colorectal cancer

Received date: April 5, 2019. Accepted: June 25, 2019, Published: June 29, 2019 


\section{Introduction:}

Human colorectal cancer (CRC) is one of the most common malignancies worldwide (Kinzler and Vogelstein, 1996). Despite years of intensive work on surgical techniques and adjuvant chemotherapies, CRC remains a highly prevalent and lethal malignancy (Goodwin and Asmis, 2009; Mishra et al., 2013). The poor prognosis is attributed to the severe toxic side effects of the current therapeutic regimes (Akhtar et al., 2014). Hence, novel less toxic treatment strategies are urgently needed to improve the poor prognosis of CRC.

Phytochemicals and their semi-synthetic and synthetic derivatives are a major source for anticancer drugs (Seca and Pinto, 2018). Some reports indicated that the herb Coptis chinensis possesses promising anti-cancer properties. Berberine, the most active ingredient in this herb, is a famous isoquinoline alkaloid that has been used for decades as an anti-microbial and anti-diarrheal agent (Kong et al., 2004). Berberine also has been shown to possess several pharmacological activities, including antiarrhythmic (Lau et al., 2001), anti-diabetic (Yin et al., 2008), and anti-oxidative properties (Racková et al., 2004). Also, this compound is well-known for its low toxicity and low cost, thus, berberine is recently catching considerable attention as a potent anticancer agent. Several previous reports showed that berberine possesses anti-tumor properties against cancer cells (Chen, 2016; Mantena et al., 2006; Yu et al., 2015). Some reports showed that berberine inhibits cell growth and promote apoptosis in various cancer cell types, for example, prostatic, hepatic, skin, and mammary human cancer cells (Choi et al., 2009; Letasiová et al., 2006; Lin et al., 2006; Patil et al., 2010). However, the possible effect of berberine on the cell cycle dynamics and apoptosis induction in colorectal cancer has not been previously investigated.

In general, the previously mentioned in vitro studies were usually based on the traditional twodimensional (2D) monolayer cultures which, to a large extend, hinder the critical role of the microenvironment as well as the cell-cell interaction in the cellular response to therapy. Therefore, the translation of the findings from the traditional 2D culture-based experiments to experimental outcomes showed only partial relevance in vivo (Wenzel et al., 2014). Cells cultured as multicellular tumor spheroids show strong proliferation gradients that reflect distribution gradients of oxygen, nutrients, and metabolites as in native tissues (Hirschhaeuser et al., 2010; Minchinton and Tannock, 2006; Tredan et al., 2007). Hence, 3D cancer cell culture models have gained interest, as it is more physiological compared to the 2D cultures and mimic the complex microenvironment of tumor tissue in vivo.

Therefore, this work aims to elucidate the antitumor efficacy of berberine using a 3D spheroid model. Also, the mechanistic role of berberine in the cell cycle, proliferation, and apoptosis in 3D culture conditions in colorectal cancer will be investigated.

\section{Material and methods: \\ Chemicals}

Berberine (Purity, 96\%) was purchased from Sigma, Germany. A stock solution of $100 \mathrm{mM}$ was prepared by dissolving $368.4 \mathrm{mg}$ of berberine in $10 \mathrm{ml}$ DMSO. Further dilutions were prepared whenever necessary by diluting the stock solution in DMSO. The toxic effect of DMSO was minimized by keeping the DMSO concentration level as low as $0.001 \%$ in all experiments.

\section{Cell culturing}

HCT116 (human colon cancer) cell line was a kind gift from Dr. Daniel Fisher (Cell cycle and control group, CNRS, Montpellier, France). Cells were grown in Dulbecco modified Eagle medium (DMEM-high glucose with L-Glutamine, Lonza Bioscience, China) supplemented with $10 \%$ fetal bovine serum (Sigma, HyClone, USA). Cells were grown under standard cell culture conditions at $37^{\circ} \mathrm{C}$ in a humidified $\mathrm{CO}_{2}$ incubator containing $5 \%$ $\mathrm{CO}_{2}$.

\section{Multicellular tumor spheroids}

Tumor spheroids were initiated in 96-well plates as previously described in Friedrich et al. (Friedrich et al., 2009). Briefly, each well was coated with $40 \mu \mathrm{l}$ of $1.5 \%$ sterile agarose (Axygen, Spain) in DMEM. 
Spheroids were initiated by seeding 1500 cells in $200 \mu 1$ of complete culture medium (DMEM, 10\% FBS) per well. Four days after seeding, spheroids with a diameter of $350-400 \mu \mathrm{m}$ were formed. Treatments were started at this time point by exchanging $50 \%$ of the $200 \mu 1$ medium with $100 \mu 1$ of fresh medium containing the desired concentration of berberine ( $2 x$ final concentration). For control conditions (DMSO-treated spheroids), $100 \mu 1$ of media were replaced with fresh DMSOcontaining medium. Media were routinely replaced every three days as described above. A minimum of 4 spheroids was analyzed per condition.

Volume and integrity of each spheroid were monitored starting at day 4 and, every 3 days up to day 28. Phase-contrast images were acquired with a $4 \mathrm{x}$ objective using an inverted microscope (Optika, Italy). All phase-contrast images of the formed spheroids were checked, and any deformed or irregular shaped spheroids were eliminated from our calculations. Spheroid volume was analyzed using ImageJ (ver. 1.5) with a macro automating size measurement for phase-contrast spheroid images (Ivanov et al., 2014). The measured area (A) of phase-contrast $2 \mathrm{D}$ projection of spheroids was used to calculate the radius $(R)$ and the volume $(V)$ of an equivalent sphere (Bacevic et al., 2017).

\section{Cell proliferation assay and doubling time calculation}

Cells (250k cell/dish) were seeded in $60 \mathrm{~mm}^{2}$ dishes. After $24 \mathrm{~h}$, the cultures were treated with berberine or DMSO. Two days after treatment, the cultures were trypsinized and counted using Hemocytometer. The suspended cells were washed with PBS, centrifuged, resuspended in $1 \mathrm{ml}$ of $80 \%$ pre-chilled $\mathrm{EtOH}$, and stored at $20{ }^{\circ} \mathrm{C}$ for cell cycle analysis. The doubling time was calculated using Roth V. 2006 Doubling Time Computing online tool (http://www.doublingtime.com/compute_more.php).

\section{Dissociation of spheroids}

Three spheroids of each condition were collected in a $1.5 \mathrm{ml}$ Eppendorf tube and dissociated by a mixed enzymatic treatment (using $0.05 \%$ trypsin, $15 \mathrm{~min}$ ), and mechanical disaggregation (by pipetting up and down three times). Cells were washed with PBS, fixed in $80 \%$ pre-chilled EtOH, and stored at $-20{ }^{\circ} \mathrm{C}$ for cell cycle analysis.

\section{Flow cytometry - cell cycle analysis}

Fixed cells were pelleted by centrifugation at $5000 \mathrm{rpm}$ for $5 \mathrm{~min}$. The cell pellet was resuspended in $0.5 \mathrm{ml}$ of Propidium Iodide (PI) (Fluka, Country) staining solution $(20 \mu \mathrm{g} / \mathrm{ml} \mathrm{PI}$, $100 \mu \mathrm{g} / \mathrm{ml}$ RNase A (Tiangen, Country), $0.1 \%$ TritonX in PBS) for $10 \mathrm{~min}$ at room temperature. The prepared samples were analyzed using BD FACS Calibur (BD Biosciences, SanJose, CA). Data were acquired and recorded using the Cellquest software (LLC 2006-2016). In general, samples were analyzed at a low flow rate and 10000 events were acquired for each sample. Forward and Side scatter aggregates of cells were determined using linear scale SSC/FSC dot plots. PI histograms were generated by acquiring the Fl2 channel events at a linear scale. The cell cycle distribution was analyzed with FlowJo v10 software.

\section{DAPI staining}

Dissociated spheroid cells were pelleted by centrifugation at $5000 \mathrm{rpm}$ for $5 \mathrm{~min}$. The pellet was resuspended in $0.5 \mathrm{ml}$ of $0.2 \%$ TritonX in PBS for $20 \mathrm{~min}$. Cells then were centrifuged, washed with PBS, and stained with DAPI staining solution $(25 \mu \mathrm{g} / \mathrm{ml}$ DAPI in PBS) for $5 \mathrm{~min}$ at room temperature. Stained cells were mounted over glass slides and analyzed with an Olympus BX41 fluorescence microscope (Olympus, Japan). Images were acquired using the Olympus C5050 camera and analyzed using Image J software.

\section{BrdU staining}

The prepared cultures were pulse-labeled $(20 \mathrm{~min})$ with bromodeoxyuridine (BrdU, $10 \mu \mathrm{M}$; Sigma Aldrich). Cells were rinsed once with PBS, trypsinized, and harvested in $15 \mathrm{ml}$ falcon tubes. The cell suspension was centrifuged and resuspended in $200 \mu \mathrm{l}$ cold PBS, fixed with $800 \mu \mathrm{l}$ ice-cold $100 \%$ ethanol, and stored in $-20^{\circ} \mathrm{C}$ until analysis. Fixed cells were permeabilized with $2 \mathrm{~N}$ $\mathrm{HCl}$ and $0.5 \%$ Triton $\mathrm{X}-100$ for $30 \mathrm{~min}$ and stained 
with anti-BrdU antibody (BD 347580, No.408) at 1:20 in PBS and incubated $2 \mathrm{~h}$ at room temperature. Cells were washed once with PBS and were stained using an IHC detection kit (Thermo Scientific, UK), according to the manufacturer's protocol.

\section{Annexin V staining}

Cells were washed twice with $1 \mathrm{~mL}$ of $1 \times$ Binding Buffer and centrifuge at $300 \times \mathrm{g}$ for 10 minutes. The cell pellet was resuspended in $100 \mu \mathrm{L}$ of $1 \times$ Binding Buffer and was stained by adding $10 \mu \mathrm{L}$ of Annexin V-FITC (Miltenyi Biotec GmbH, Germany) for 15 $\min$ at RT. The cells were washed twice by $1 \times$ Binding Buffer and centrifuge at $300 \times \mathrm{x}$ for 10 minutes and resuspend in $500 \mu \mathrm{L}$ of $1 \times$ Binding Buffer. Propidium iodide solution $(5 \mu \mathrm{L})$ was added immediately before analysis. The prepared samples were analyzed using flow cytometry.

\section{KI67 staining}

Cells were blocked specimen in Blocking Buffer for $10 \mathrm{~min}$ and centrifuge at $300 \times \mathrm{x}$ for 10 minutes.

After aspirating the blocking reagent, the sample was incubated with Anti-Ki-67 (D3B5) Rabbit mAb
(Alexa Fluor® 488 Conjugate) \#11882 for $2 \mathrm{~h}$ at $4^{\circ} \mathrm{C}$. Cells were rinsed once in PBS and analyzed using flow cytometry.

\section{Statistical analysis}

Significant differences between experimental groups were determined using a two-tailed Student's $t$-test in Excel 2016 (Microsoft, USA). Our results were considered statistically significant when $p$-value $<0.05$.

\section{Results:}

\section{Berberine inhibits HCT-116 spheroid growth}

HCT-116 cancer cell spheroids were treated with a series of berberine concentrations $(1,10,20,50 \mu \mathrm{M})$ (Fig. 1A). A direct temporal and dose-dependent reduction in the volume of spheroids in response to berberine treatment was observed (Fig. 1B). The higher the dose of berberine results in a greater reduction in the spheroid size. The difference between the berberine-treated $(10,20,50 \mu \mathrm{M})$ and control samples was statistically significant $(p<$ 0.05 ) on days 10 and 13.

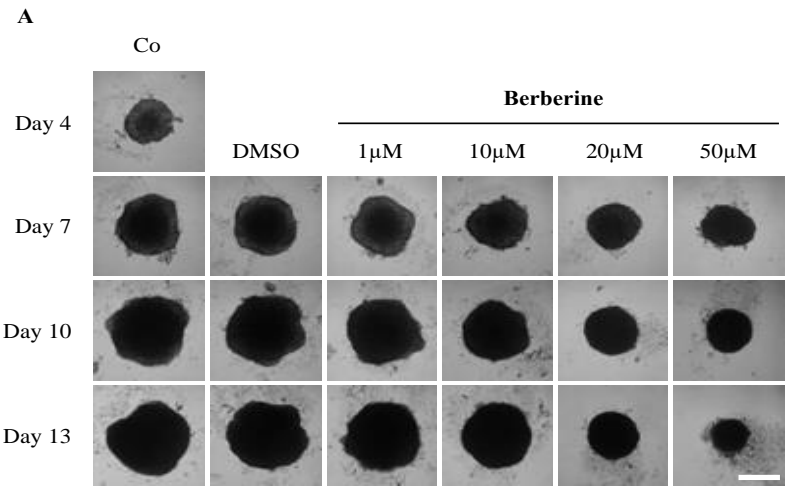

B

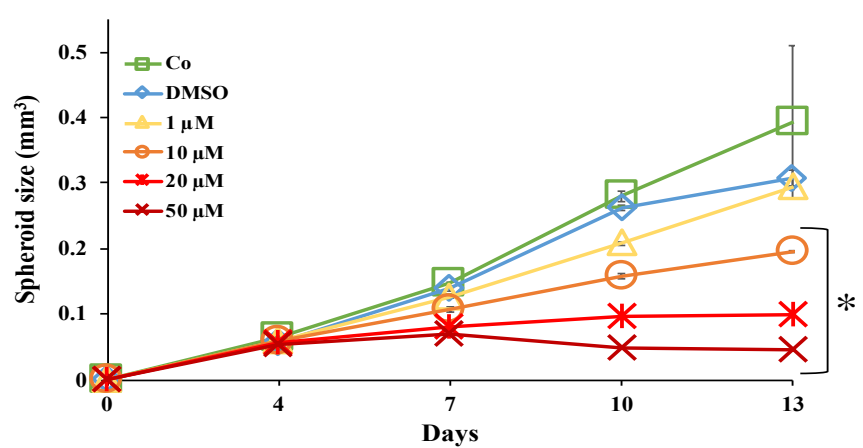

Figure 1. Berberine inhibits tumor spheroid growth of HCT116 cells. A. Representative phase-contrast photographs of untreated, DMSO-treated, and berberine-treated spheroids. B. Growth curves of untreated, DMSO-treated, and berberine-treated spheroids showing show the growth suppressing effect of berberine. Bar. $400 \mu \mathrm{m}$. Results are mean \pm s.d. $\left(\mathrm{n}=2\right.$, Student's $t$-test, $\left.{ }^{*} p<0.05\right)$. 


\section{Berberine attenuates the proliferative capacity of HCT116 cancer cells}

A proliferation assay was performed to investigate the possible effect of Berberine on the proliferation potential of cells. The obtained results showed that berberine-treated $(20 \mu \mathrm{M})$ cultures possess lower cell counts (significantly decreased by $50 \%$ ) as compared to controls (Fig. 2A). Also, when calculating the doubling time of cells, berberine-treated cells showed higher doubling time as compared to the control cells (Fig. 2B). Further, cell culture preparations were labeled for the proliferation marker (Ki67) and analyzed using flow cytometry. The results show no difference in the level of Ki67 staining between berberine-treated and control cultures (Fig. 2C).
A

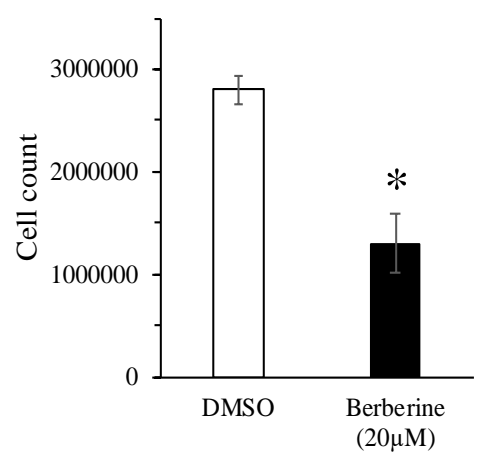

C

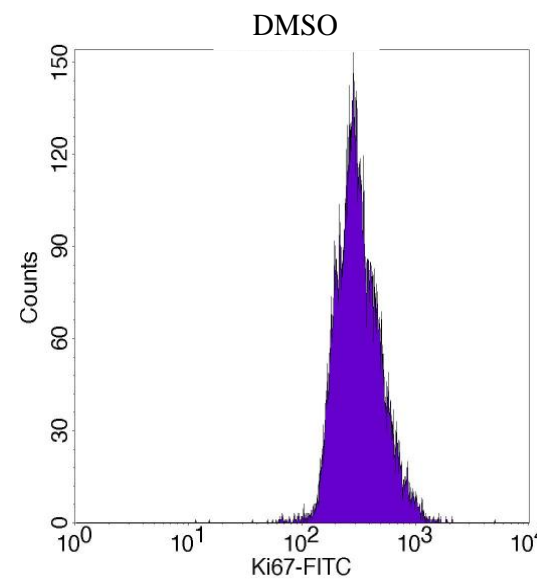

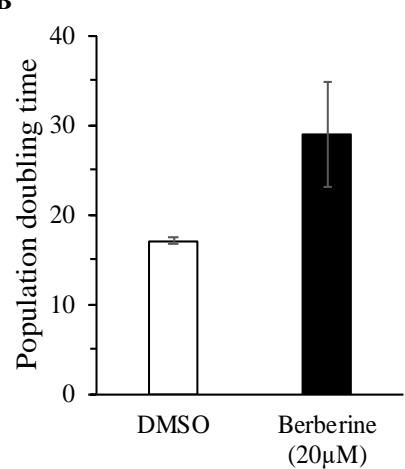

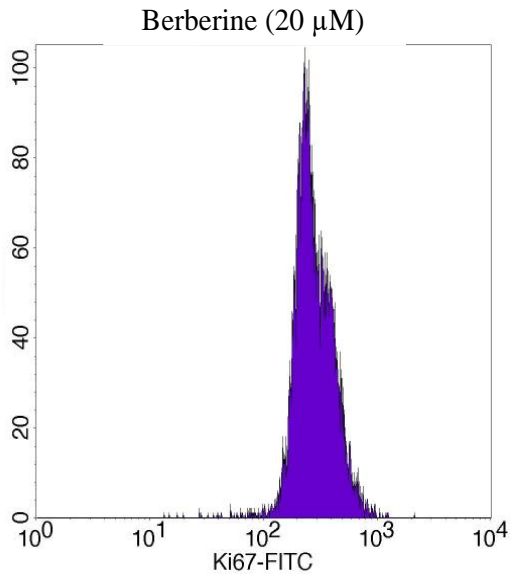

Figure 2. Berberine attenuates the proliferative potential of HCT116 cells. A. Bar graph showing the cell count of DMSO and berberine-treated cultures $48 \mathrm{~h}$ after treatment. B. Bar graph showing the variation in the doubling time of cancer cells upon treatment with berberine. C. KI67 histograms of DMSO and berberine-treated cultures. $(n=2)$. Results are mean \pm s.d. $(\mathrm{n}=2$, Student's $t$-test, $* p<0.05)$. 


\section{Effect of berberine on the cell cycle progression of spheroid cancer cells}

To investigate the possible role of Berberine on the cell cycle progression of cancer cells, spheroids were dissociated into cell suspensions and were analyzed using flow cytometry. The obtained results show that berberine application induces alternations in the cell cycle distribution of cells as compared to controls (Fig. 3A). The $\%$ of G1 fraction of cells in berberinetreated spheroids was elevated (46\%) compared to controls (36\%). Interestingly, the S-phase fraction possesses only $13 \%$ of the population in berberinetreated samples compared to $23 \%$ in the control A

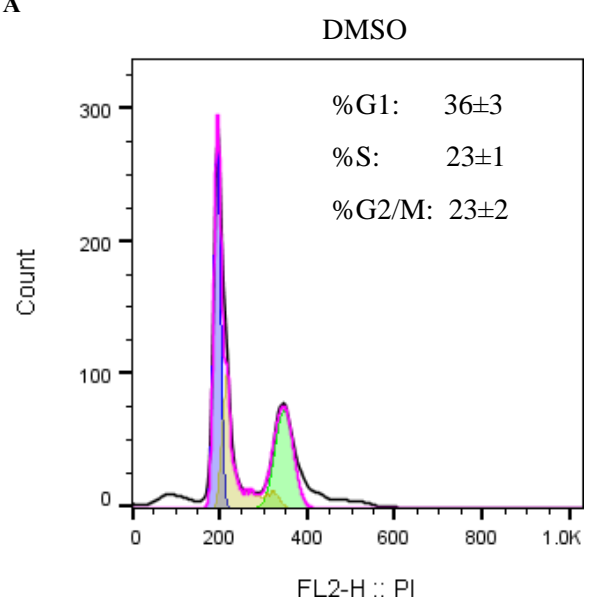

B

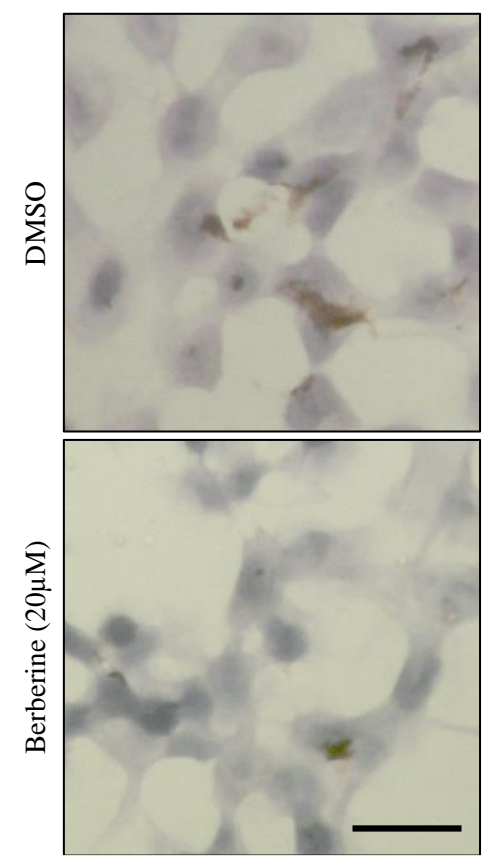

samples. i.e. berberine application induced a significant reduction in the $\mathrm{S}$ phase fraction by $44 \%$. A very slight change was observed in the $\mathrm{G} 2 / \mathrm{M}$ phase fraction. Moreover, a sub-G1 fraction of cells was found in the control samples only. The previous finding regarding the S-phase fraction of cells was further investigated using BrdU labeling upon berberine or DMSO treatment in 2D cultures (Fig. 3B). BrdU positive and negative cells at 5 different regions of the stained culture were counted (Fig. 3C). In coincidence with the previous finding, the data show that the $\%$ BrdU positive cells was $40 \%$ lower in berberine-treated samples as compared to controls.

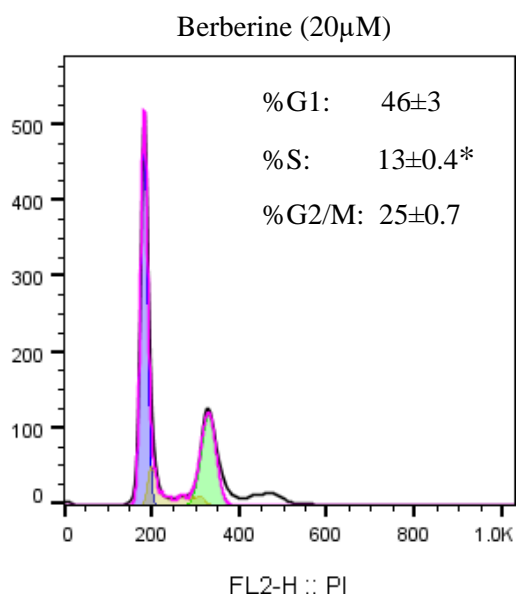

C

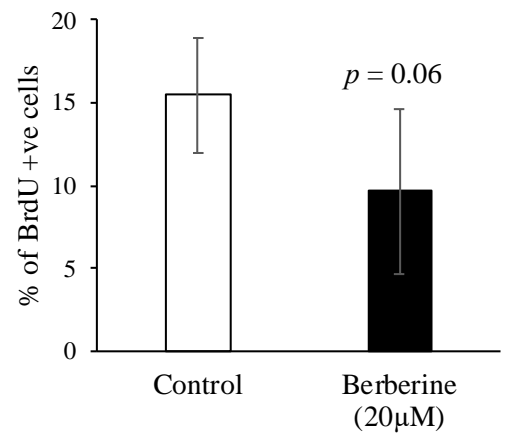

Figure 3. The effect of Berberine on the cell cycle profile of HCT116 cancer cell spheroids. Histograms showing the cell cycle distribution of DMSO and Berberine-treated spheroids. Spheroid samples were dissociated using a mixed mechanical and enzymatic method. Cell suspension from spheroid cultures was stained with PI and analyzed using a flow cytometer. B. Phase-contrast images of BrdU-immunostained cultures upon treatment with DMSO or Berberine (20 $\mu \mathrm{M})$. Samples were counterstained with hematoxylin. Bar. $50 \mu \mathrm{m}$. C. Bar graph showing the $\%$ of BrdU positive cells upon DMSO or berberine treatment. Results are mean \pm s.d. $(\mathrm{n}=2$, Student's $t$-test, $* p<0.05)$. 


\section{Determination of Apoptosis on HCT116 cancer cells upon berberine treatment}

As the cell cycle disturbance upon berberine treatment might activate the programmed cell death, it was necessary to evaluate the level of apoptosis in cells in response to berberine treatment. The apoptotic cell fraction was assessed using the Annexin V-FITC/PI staining (Fig. 4A). The apoptotic cell fraction was extremely low in both berberinetreated as well as control cultures and no significant difference was found between both cultures. Also, DAPI staining was applied to further investigated the berberine-treated and control cultures for alternations in the nuclear morphology. The obtained results show that berberine application did not induce any apoptotic features in the nuclei of cells (Fig. 4B).
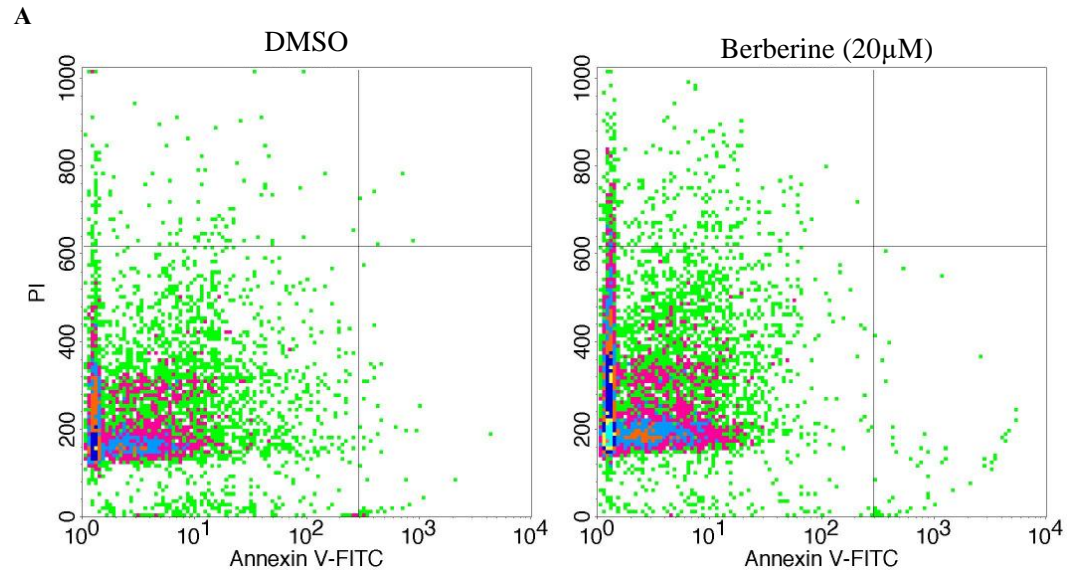

B
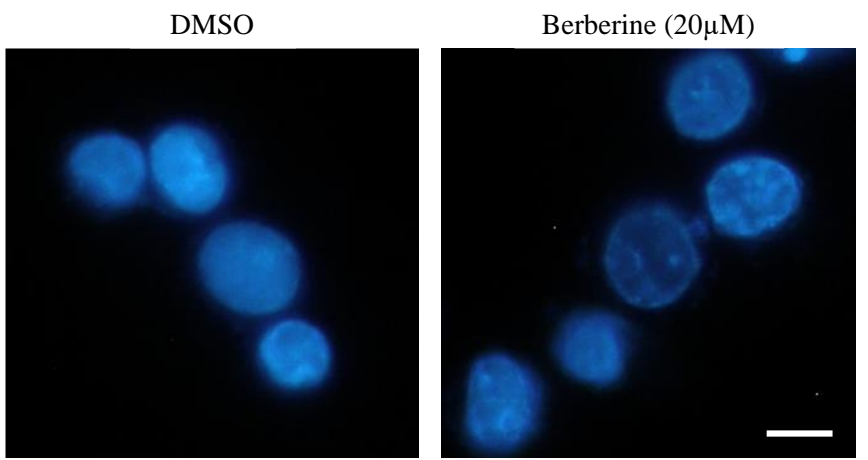

Figure 4. The impact of berberine on the apoptosis of HCT116 cancer cells. A. Annexin V/PI Dot plots of DMSO and berberine-treated cultures. B. DAPI stained preparations of berberine-treated and control cells. Bar. 10 $\mu \mathrm{m} .(\mathrm{n}=2)$.

\section{Discussion:}

Colorectal cancers are among the most common malignancies worldwide with a relatively poor prognosis due to the high toxicity of the current therapeutic regimes (Akhtar et al., 2014). Hence, novel less toxic treatment strategies are urgently needed to improve the poor prognosis of CRC. Berberine is a natural alkaloid with several anticancer properties that have been previously investigated (Chen, 2016; Letasiová et al., 2006; Patil et al., 2010). However, these investigations were usually performed using the traditional 2D cultures which hinder the critical role of the microenvironment as well as the cell-cell interaction in the cellular response to therapy. Critically, these interactions usually promote cell survival and resistance to therapy. Also, 3D tumor spheroids reproduce several parameters of tumors in situ (including metabolic products, oxygen, and nutrient concentrations). Therefore, the 3D model has been recently regarded as a better model for studying the efficacy of potential anti-cancer agents (Wenzel et al., 2014). Hence, this work investigated the anticancer efficacy of berberine using a more physiological 3D multicellular spheroid model of HCT116 colorectal cells. Specifically, the 3D growth inhibitory effect, cell cycle distribution, and 
induction of apoptosis in berberine-treated cultures were assessed.

When investigating its effect on the rate of growth, berberine showed strong anti-growth potential on HCT116 colorectal spheroids at relatively low concentration $(10 \mu \mathrm{M})$. Previous studies regarding the growth inhibitory effect of berberine on colorectal $3 \mathrm{D}$ in vitro models are lacking. However, previous studies showed that berberine inhibits cancer cell monolayer cultures of lung, liver, breast, and leukemic cancer cells (Balakrishna and Kumar, 2015; Tan et al., 2011). In coincidence with the previous findings, berberine attenuated the proliferation potential of cells in 2D cultures. Also, the doubling time of cells was estimated and found to be dramatically decreased in response to berberine application. Several previous studies indicated that berberine acted to inhibit the proliferation of colon cancer cells (Wang et al., 2013).

As the doubling time of cells depends on the cell cycle activity, these results indicate a possible disturbance in the cell cycle dynamics of cells upon berberine application. For this reason, a flow cytometric analysis on cell suspensions from dissociated spheroids was performed. The results indicate that berberine induces a clear G1 phase arrest. Consequently, the $\mathrm{S}$ phase fraction of cells decreased. The effect of the berberine on the cell cycle has not been previously investigated using a 3D culture model, however, some 2D culture reports are available. Mantena and colleagues showed that berberine induces G1-phase cell cycle arrest in vitro human prostate carcinoma cells (Mantena et al., 2006).

Considering that the HCT116 cells carry a wild type p53 gene, the prolonged cell cycle arrest due to berberine treatment is more likely to promote apoptosis. This has previously described in several reports in vitro on prostate carcinoma (Mantena et al., 2006), Osteosarcoma (Chen, 2016; Zhu et al., 2014), gastric carcinoma (Lin et al., 2006), Hepatocellular carcinoma (Yip and Ho, 2013; Yu et al., 2015), breast carcinoma (Xie et al., 2015) cells. Unexpectedly, berberine did not induce any significant level of apoptosis in cancer cells in neither the 3D nor the 2D culture preparations.

Taken together, the results show that berberine possesses a strong anti-tumor efficacy in 3D culture preparations of HCT116 cells. Also, berberine modulates the cell cycle progression and, thereby, attenuates the replicative capacity of cancer cells. Therefore, berberine could be considered an effective anti-proliferative agent. Notably, berberine is not pro-apoptotic in HCT116 3D spheroid cultures.

\section{References:}

Akhtar, R., Chandel, S., Sarotra, P., Medhi, B., 2014. Current status of pharmacological treatment of colorectal cancer. World J. Gastrointest. Oncol. 6, 177-183. https://doi.org/10.4251/wjgo.v6.i6.177

Bacevic, K., Noble, R., Soffar, A., Wael Ammar, O., Boszonyik, B., Prieto, S., Vincent, C., Hochberg, M.E., Krasinska, L., Fisher, D., 2017. Spatial competition constrains resistance to targeted cancer therapy. Nat. Commun. 8, 1995. https://doi.org/10.1038/s41467-017-01516-1

Balakrishna, A., Kumar, M.H., 2015. Evaluation of Synergetic Anticancer Activity of Berberine and Curcumin on Different Models of A549, Hep-G2, MCF-7, Jurkat, and K562 Cell Lines. BioMed Res. Int. 2015, 1-7. https://doi.org/10.1155/2015/354614

Chen, Z.-Z., 2016. Berberine Induced Apoptosis of Human Osteosarcoma Cells by Inhibiting Phosphoinositide 3 Kinase/Protein Kinase B (PI3K/Akt) Signal Pathway Activation. Iran. J. Public Health 45, 578-585.

Choi, M.S., Oh, J.H., Kim, S.M., Jung, H.Y., Yoo, H.S., Lee, Y.M., Moon, D.C., Han, S.B., Hong, J.T., 2009. Berberine inhibits p53dependent cell growth through induction of apoptosis of prostate cancer cells. Int. J. Oncol. 34, 1221-1230.

Friedrich, J., Seidel, C., Ebner, R., Kunz-Schughart, L.A., 2009. Spheroid-based drug screen: considerations and practical approach. Nat. Protoc. 4, 309-324. https://doi.org/10.1038/nprot.2008.226

Goodwin, R.A., Asmis, T.R., 2009. Overview of systemic therapy for colorectal cancer. Clin. Colon Rectal Surg. 22, 251-256. https://doi.org/10.1055/s-0029-1242465

Hirschhaeuser, F., Menne, H., Dittfeld, C., West, J., Mueller-Klieser, W., Kunz-Schughart, L.A., 2010. Multicellular tumor spheroids: An underestimated tool is catching up again. J. Biotechnol. 148, 3-15. https://doi.org/10.1016/j.jbiotec.2010.01.01 2

Ivanov, D.P., Parker, T.L., Walker, D.A., Alexander, C., Ashford, M.B., Gellert, P.R., Garnett, M.C., 2014. Multiplexing spheroid volume, 
resazurin and acid phosphatase viability assays for high-throughput screening of tumour spheroids and stem cell neurospheres. PloS One 9, e103817. https://doi.org/10.1371/journal.pone.010381 7

Kinzler, K.W., Vogelstein, B., 1996. Lessons from hereditary colorectal cancer. Cell 87, 159170.

Kong, W., Wei, J., Abidi, P., Lin, M., Inaba, S., Li, C., Wang, Yanling, Wang, Z., Si, S., Pan, H., Wang, S., Wu, J., Wang, Yue, Li, Z., Liu, J., Jiang, J.-D., 2004. Berberine is a novel cholesterol-lowering drug working through a unique mechanism distinct from statins. Nat. Med. 10, 1344-1351. https://doi.org/10.1038/nm1135

Lau, C.W., Yao, X.Q., Chen, Z.Y., Ko, W.H., Huang, Y., 2001. Cardiovascular actions of berberine. Cardiovasc. Drug Rev. 19, 234244.

Letasiová, S., Jantová, S., Cipák, L., Múcková, M., 2006. Berberine-antiproliferative activity in vitro and induction of apoptosis/necrosis of the U937 and B16 cells. Cancer Lett. 239, 254-262. https://doi.org/10.1016/j.canlet.2005.08.024

Lin, J.-P., Yang, J.-S., Lee, J.-H., Hsieh, W.-T., Chung, J.-G., 2006. Berberine induces cell cycle arrest and apoptosis in human gastric carcinoma SNU-5 cell line. World J. Gastroenterol. 12, 21-28.

Mantena, S.K., Sharma, S.D., Katiyar, S.K., 2006. Berberine, a natural product, induces G1phase cell cycle arrest and caspase-3dependent apoptosis in human prostate carcinoma cells. Mol. Cancer Ther. 5, 296$308 . \quad$ https://doi.org/10.1158/15357163.MCT-05-0448

Minchinton, A.I., Tannock, I.F., 2006. Drug penetration in solid tumours. Nat. Rev. Cancer 6, 583-592. https://doi.org/10.1038/nrc1893

Mishra, J., Drummond, J., Quazi, S.H., Karanki, S.S., Shaw, J.J., Chen, B., Kumar, N., 2013. Prospective of colon cancer treatments and scope for combinatorial approach to enhanced cancer cell apoptosis. Crit. Rev. Oncol. Hematol. 86, 232-250. https://doi.org/10.1016/j.critrevonc.2012.09. 014

Patil, J.B., Kim, J., Jayaprakasha, G.K., 2010. Berberine induces apoptosis in breast cancer cells (MCF-7) through mitochondrialdependent pathway. Eur. J. Pharmacol. 645,
70-78.

https://doi.org/10.1016/j.ejphar.2010.07.037

Racková, L., Májeková, M., Kost'álová, D., Stefek, M., 2004. Antiradical and antioxidant activities of alkaloids isolated from Mahonia aquifolium. Structural aspects. Bioorg. Med. Chem. 12, 4709-4715. https://doi.org/10.1016/j.bmc.2004.06.035

Seca, A., Pinto, D., 2018. Plant Secondary Metabolites as Anticancer Agents: Successes in Clinical Trials and Therapeutic Application. Int. J. Mol. Sci. 19, 263. https://doi.org/10.3390/ijms19010263

Tan, W., Li, Chen, M., Wang, Y., 2011. Berberine hydrochloride: anticancer activity and nanoparticulate delivery system. Int. J. Nanomedicine 1773. https://doi.org/10.2147/IJN.S22683

Tredan, O., Galmarini, C.M., Patel, K., Tannock, I.F., 2007. Drug Resistance and the Solid Tumor Microenvironment. JNCI J. Natl. Cancer Inst. $\quad 99, \quad 1441-1454$. https://doi.org/10.1093/jnci/djm135

Wang, L., Cao, H., Lu, N., Liu, L., Wang, B., Hu, T., Israel, D.A., Peek, R.M., Polk, D.B., Yan, F., 2013. Berberine Inhibits Proliferation and Down-Regulates Epidermal Growth Factor Receptor through Activation of $\mathrm{Cbl}$ in Colon Tumor Cells. PLoS ONE 8, e56666. https://doi.org/10.1371/journal.pone.005666 6

Wenzel, C., Riefke, B., Gründemann, S., Krebs, A., Christian, S., Prinz, F., Osterland, M., Golfier, S., Räse, S., Ansari, N., Esner, M., Bickle, M., Pampaloni, F., Mattheyer, C., Stelzer, E.H., Parczyk, K., Prechtl, S., Steigemann, P., 2014. 3D high-content screening for the identification of compounds that target cells in dormant tumor spheroid regions. Exp. Cell Res. 323, 131143.

https://doi.org/10.1016/j.yexcr.2014.01.017

Xie, J., Xu, Y., Huang, X., Chen, Y., Fu, J., Xi, M., Wang, L., 2015. Berberine-induced apoptosis in human breast cancer cells is mediated by reactive oxygen species generation and mitochondrial-related apoptotic pathway. Tumor Biol. 36, 12791288. https://doi.org/10.1007/s13277-0142754-7

Yin, J., Gao, Z., Liu, D., Liu, Z., Ye, J., 2008. Berberine improves glucose metabolism through induction of glycolysis. Am. J. Physiol. Endocrinol. Metab. 294, E148-156. https://doi.org/10.1152/ajpendo.00211.2007 
Yip, N.K.Y., Ho, W.S., 2013. Berberine induces apoptosis via the mitochondrial pathway in liver cancer cells. Oncol. Rep. 30, 11071112. https://doi.org/10.3892/or.2013.2543

Yu, Y., Champer, J., Beynet, D., Kim, J., Friedman, A.J., 2015. The role of the cutaneous microbiome in skin cancer: lessons learned from the gut. J. Drugs Dermatol. JDD 14, 461-465.

Zhu, Y., Ma, N., Li, H.-X., Tian, L., Ba, Y.-F., Hao, B., 2014. Berberine induces apoptosis and DNA damage in MG-63 human osteosarcoma cells. Mol. Med. Rep. 10, 1734-1738.

https://doi.org/10.3892/mmr.2014.2405 